\title{
1. The engines of the creative response: the introductory framework
}

\section{Cristiano Antonelli}

\section{INTRODUCTION}

The Schumpeterian notion of creative response provides a consistent framework in which it is possible to articulate a comprehensive and coherent account of the endogenous determinants of the introduction of innovations. Firms caught in out-of-equilibrium conditions try to react to unexpected conditions of product and factor markets, and hence levels of profitability and performances away from the normal. Their reaction can be either adaptive or creative. When adaptive responses prevail, firms can only change their techniques in the existing map of isoquants: the system converges to equilibrium. When their response is creative firms can actually introduce new technologies that change the existing map of isoquants. The chances that the reaction is creative and the introduction of innovations successful are contingent upon the amount of knowledge externalities the system in which the firms are embedded is able to provide. The availability of external knowledge at costs below equilibrium levels supports their creative response and makes the introduction of productivity-increasing innovations possible.

The introduction of innovations feeds further out-of-equilibrium conditions that in turn push firms towards creative responses that may succeed, again with the eventual introduction of new innovations, provided the dynamics has not reduced the quality of knowledge governance mechanisms. In this case the system enters a positive loop of feedbacks where all the components - out-of-equilibrium conditions, knowledge generation, knowledge governance and innovation - are endogenous. The tools of evolutionary complexity apply.

When the system is not able to provide access to knowledge spillovers at low costs, the response of firms is doomed to be adaptive. When the system does not provide the necessary access at low costs to the stock of quasipublic knowledge, firms can try to change their techniques rather than their technologies: the system gravitates around equilibrium conditions without growth and change. The tools of equilibrium economics apply. 
When the response of firms to out-of-equilibrium conditions is creative and strong, and the system supports them with persistent knowledge externalities that provide access to the stock of the existing quasi-public knowledge at low costs, the system is able to foster the rate of technological change and reproduce out-of-equilibrium conditions that may last until the quality of knowledge governance mechanisms stays put (Antonelli, 2008, 2011, 2015a, 2017a, b).

The dynamics of the innovation process is fully endogenous to the system and exhibits the typical characteristics of an emergent system property (Arthur, 2007, 2009, 2014; Foster and Metcalfe, 2012). The successful introduction of innovation is in fact the result of the interaction between individual action and the properties of the system (Roberts et al., 2017).

This chapter contributes to the framework outlined so far with analysis of the role of: i) the levels of reactivity of firms to out-of-equilibrium conditions; ii) the quality of knowledge governance mechanisms at work within economic systems that define the actual amount of knowledge externalities available to reactive firms in assessing the rate of technological change.

Section 2 explores the evolutionary complexity of the interaction between endogenous out-of-equilibrium conditions, creative response and knowledge externalities that can be elaborated from the foundations laid down by Schumpeter's essay 'The creative response in economic history'. Section 3 analyses the relationship between out-of-equilibrium conditions and firms' responses, focusing on the levels of firms' reactivity. Section 4 recalls the role of knowledge externalities in making the creative response possible and effective, focusing on the endogenous dynamics of knowledge governance mechanisms. Section 5 presents a simple model that enables us to explore the systemic and endogenous dynamics of the creative response. The conclusions summarize the results and explore their implications for both economic and policy analysis.

\section{THE EVOLUTIONARY COMPLEXITY OF ENDOGENOUS INNOVATION}

In 'The creative response in economic history', published in the Journal of Economic History in 1947, Joseph Schumpeter provides a synthesis of the alternative views about the relationship between performances and innovation he presented in 1939 and 1942 in Business Cycles and Capitalism, Socialism and Democracy (Antonelli, 2008, 2015a, 2017a, b).

In Business Cycles Schumpeter elaborates the view that firms are induced to introduce innovations to cope with decline of performance. 
His historic analysis of innovation flows shows that the introduction of innovations peaks in the years of depression that follow the exhaustion of opportunities provided by previous gales of innovation. Firms are exposed to a decline in performance: the growth of output is weak; profitability falls below the average; and, ultimately, even actual losses emerge. The survival of firms is actually endangered. The introduction of innovations is regarded as a necessity to contrast the fall of performance below the average and possible risks of failure and exit. The generalized conditions of declining performance shared by many firms induce a collective innovation process that eventually leads to the emergence of new gales characterized by the complementarity and interoperability of a variety of new technologies. Business Cycles elaborates the 'failure inducement' mechanism, eventually articulated by Nelson and Winter (1982), according to which innovations are more likely to be introduced where profits and performance are below equilibrium and/or average levels.

A few years later, Capitalism, Socialism and Democracy provides an alternative framework where the relationship between performances and innovation is reversed. Firms that enjoy extra profits are more likely to engage in risky undertakings such as research and development (R\&D) activities that are at the origin of the possible introduction of innovations. Firms with profits and performance above average and above equilibrium levels are more likely to introduce innovations also because they can fund the necessary research with internal financial resources. Profits above equilibrium reduce levels of risk aversion and liquidity constraints. Capitalism, Socialism and Democracy laid down the foundations of the well-known Schumpeterian hypothesis according to which rates of innovation are faster in oligopolistic markets characterized by the rivalry between large corporations with performances well above equilibrium levels.

The analysis of Capitalism, Socialism and Democracy contrasts that of Business Cycles. Although the focus and level of the analyses differ the former elaborates at the aggregate level and focuses on the working of the system while the latter is typically microeconomic and impinges upon the theory of the firm - the relationship between performance and innovation is negative in the former and positive in the latter. The 1947 essay 'The creative response in economic history' seems to provide a synthesis: firms try to innovate when they try to cope with out-of-equilibrium conditions. In turn, out-of-equilibrium conditions take place both when performance is below and above equilibrium levels.

The intuition of 'The creative response in economic history' enables us to implement four important contributions that synthesize the different strands of literature that impinge upon the separate readership of the Schumpeterian legacy: 
1. It introduces the reactivity function whereby innovation takes place as a response to out-of-equilibrium conditions that can be both negative (as in Business Cycles) and positive (as in Capitalism, Socialism and Democracy).

2. It enables us to operationalize the notion of procedural rationality.

3. It stresses the crucial role of the context in which the response takes place.

4. It provides the framework to grasp the endogenous relationship between out-of-equilibrium conditions and innovation.

Let us consider these in turn.

\section{The Innovative Response}

The introduction by Schumpeter (1947) of the reactivity function can be regarded as a major contribution to economics. It encompasses and generalizes a variety of approaches: from the induced technological change approach to the demand pull and the oligopolistic rivalry, including the very basic notion of technical change of microeconomics as well as the evolutionary approach. In basic microeconomics firms 'react' to changes in factor markets and in inputs costs, searching for new existing techniques on the 'given' map of isoquants. The notion of reactive response finds here its foundations. The notion of innovative response can be regarded as a direct extension of the reactive technical change when technological change is no longer exogenous but is regarded as the endogenous outcome of firms' conduct. In the demand pull approach, firms react to changes in demand for their products, enhancing the division of labour that enables them to introduce innovations. In the induced technological change approach, firms react to changes in input costs and innovate, changing the map of (no longer given) isoquants.

Since the seminal contribution of Dasgupta and Stiglitz (1980) corporate decision-making regarding $\mathrm{R} \& \mathrm{D}$ has been analysed within the framework of the typical reaction function of oligopolistic rivalry. The evolutionary approach elaborated by Nelson and Winter (1982) assumes that firms change their routines when their performance falls below average levels: the attempt to innovate is viewed as a way of coping with emerging failures. Lazonick (2007: 27) provides quite an interesting and well-synthesized framework:

The rise of new competition poses a challenge to the innovating firm. It can seek to make an innovative response or, alternatively, it can seek to adapt on the basis of the investments that it has already made by, for example, obtaining wage and work concessions from employees, debt relief from creditors, or tax breaks or 
other subsidies from the state (see Lazonick, 1993). An enterprise that chooses the adaptive response in effect shifts from being an innovating to an optimizing firm. How the enterprise responds will depend on not only the abilities and incentives of those who exercise strategic control but also the skills and efforts that can be integrated in its organization and the committed finance that, in the face of competitive challenges, can be mobilized to sustain the innovation process.

Lazonick (1993) limits the source of out-of-equilibrium conditions to the rise of new competition. In our approach, instead, changes in both factor and product markets, at the firm and the system level, do engender out-ofequilibrium conditions.

As a matter of fact the recent literature on the widespread surge of green technologies relies systematically on the notion of innovative reaction, stressing the positive role of the upsurge of oil prices, carbon taxes and environmental constraints as well as the strong increase in demand for low-emission-production processes, capital goods and final products as determinants of the creative reaction of firms pushed to introduce new energy-saving and green technologies by unexpected out-of-equilibrium conditions (Porter and van der Linde, 1995; Newell et al., 1999; Acemoglu et al., 2012; Aghion et al., 2016). Yet this literature reveals three major limits:

- It fails to elaborate explicitly an integrated notion of innovative response that is able to frame into a single and comprehensive context that includes different sources of out-of-equilibrium conditions.

- It portrays the relationship between out-of-equilibrium conditions and innovative response as automatic and deterministic, as if all firms facing unexpected changes in their product and factor markets might actually innovate.

- It assumes that the shocks to which firms react are exogenous, and is not able to grasp their endogenous determinants.

\section{The Response as a Form of Procedural Rationality}

Schumpeterian decision-making is far from Olympian rationality. Firms make plans on the basis of their limited knowledge of the actual and expected conditions of product and factor markets. When their expectations fail, they try to elaborate responses that are highly contextual and constrained by sunk costs. The response is a form of procedural rationality. The Schumpeterian notion of creative/adaptive response complements and enriches Herbert Simon's analysis of the intrinsic limits of knowledge and the role of bounded and procedural rationality (Simon, 1947, 1979, 1982). 


\section{The Role of Externalities}

The outcome of the Schumpeterian response is not deterministic but strictly conditional on the availability of knowledge externalities. The response of firms may be creative, and leads to the actual introduction of innovations only if and when substantial knowledge externalities are available. When the quality of knowledge governance mechanisms and stocks of quasi-public knowledge are low, the actual provision of knowledge externalities falls below critical values, the reactive attempt of firms fails to be innovative and the response is just adaptive: technical change replaces technological change.

The response of firms to out-of-equilibrium changes in both their product and factor markets consists in mobilizing research activities. Such activities are necessary both to search for existing techniques that fit better with the changed conditions of product and factor markets and to introduce new technologies - that is, techniques that do not exist and do not belong to the existing map of isoquants. The search for and identification of existing techniques, new to the firm but already known, are not free and entail specific costs. In appropriate conditions determined by the properties of the system that provide substantial knowledge externalities and hence access to the stock of quasi-public knowledge at low costs, research activities enable the generation of additional knowledge that may eventually lead to the introduction of new technologies. The differences in outcome - whether it is just adaptive, as in the identification of new viable techniques among the many already available on the existing map of isoquants, or actually creative so as to enable the introduction of new technologies that reshape the map of isoquants - are determined by the amount of knowledge externalities available in the system, and hence by the bottom-line access and use costs of external knowledge (Antonelli, $2017 \mathrm{a}, \mathrm{b})$.

\section{The Endogenous Relationship between Out-of-Equilibrium Conditions and Innovation}

The introduction of innovation as the outcome of the creative response of firms to out-of-equilibrium conditions, contingent upon the quality of knowledge externalities available in the system, is itself the cause of further out-of-equilibrium conditions. Out-of-equilibrium conditions are not the result of exogenous shocks, but the endogenous consequence of the innovative response of firms. Not only are out-of-equilibrium conditions endogenous to the system, but the quality of knowledge externalities is also determined within the system and may increase as well as decrease. 
The response of firms to out-of-equilibrium conditions, in fact, consists in the generation of additional technological knowledge that is necessary to introduce innovations. The additional knowledge spills into the system and affects the size and the quality of the stock of quasi-public knowledge available for the generation of new technological knowledge. At the same time the levels of access costs to the stock of quasi-public knowledge are determined by the systems of knowledge interactions and transactions between firms and other knowledge-intensive agents.

\section{LEVELS OF REACTIVITY AND RESEARCH EFFORTS}

It seems now useful to make a step forward in analysing the crucial role of the levels of reactivity of firms that try to cope with out-of-equilibrium conditions. Decision-making is based upon procedural rationality: on one hand firms do not command the understanding of all the possible alternatives; on the other they are able to explore uncharted waters and introduce innovations and change their routines. At each point in time they try to cope with the changing conditions of product and factor markets under constraints of sunk costs and past decisions. Their ability to cope with changing economic conditions is the outcome of a variety of factors, including: the type of structure and organization; the role of shareholders and stakeholders; industrial relations and levels of entrepreneurship of top managers. Figure 1.1 compares research effort $(\mathrm{R})$ with performance levels both above and below the average (П). It exhibits two levels of reactivity. Around equilibrium levels, at the intersection of the two axes, firms do not try to change their production processes. Liquidity constraints and risk aversion restrain research efforts. The further away from equilibrium, the stronger is the likelihood that firms try to change their production

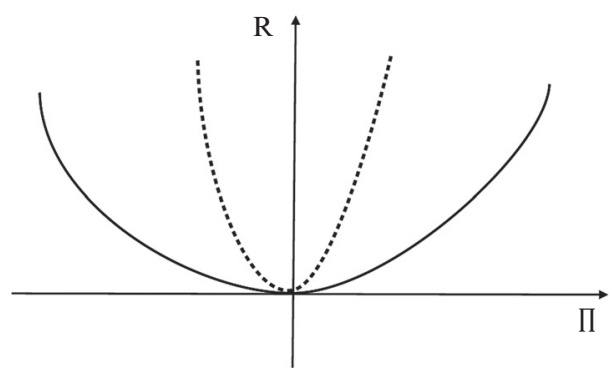

Figure 1.1 Performance and research effort: levels of reactivity 
processes either by searching for new existing techniques or by actual research activities that, provided substantial knowledge externalities are available, may enable the introduction of new technologies.

Two mechanisms are at work in this process: the failure inducement articulated by Schumpeter in Business Cycles and the success inducement analysed in Capitalism, Socialism and Democracy. Let us consider them in turn. Firms try to innovate to cope with the high risks of failure in the right quadrant where losses are greater, performance is worst and research efforts stronger. The negative conditions of performance and the high risks of failure reduce the risk aversion. The substitution of tangible investments with intangible ones and the increase in research activities are the last chance to try to cope with threats to survival. In the left quadrant, instead, the larger the profits, the better the performance and the stronger the research efforts. Firms can fund a larger budget of research activities that may put them in a position to try to innovate because of an abundance of internal cash. Large internal cash reserves reduce liquidity constraints, avoid the credit rationing of external finance and reduce the levels of risk. The possible failure of innovative undertaking does not put at risk the entrepreneurial managers who have already secured high levels of profitability for their shareholders and stakeholders. The success of the risky undertakings may yield further growth and larger profits that would benefit the managers.

Relationships between out-of-equilibrium conditions, however, can take place with different levels of elasticity. Figure 1.1 exhibits two levels of reactivity. The bold line represents low levels of reactivity: firms are reluctant to change their levels of innovative efforts. The dotted line represents high levels of reactivity. ${ }^{1}$

The key point is that the extent to which the change in the levels of (relative) performance affects the levels of research efforts. The bold line represents high levels of reactivity stemming from high levels of entrepreneurship. Firms guided by managers with high levels of entrepreneurship are more likely to exhibit high levels of reactivity to changing levels of profitability and performance at large. Firms guided by managers with low levels of entrepreneurship are less reactive.

Figure 1.2 compares levels of reactivity with levels of research effort: on the horizontal axis $\Delta \Pi$ measures in absolute terms the differences between profitability and performance of each firm and the normal and/ or average profitability and performance of all the firms in the system; on the vertical axis $\mathrm{R}$ measures levels of research effort. The levels of reactivity play an important role in assessing the amount of research carried out in order to cope with out-of-equilibrium conditions. Large research budgets may implement a creative response and introduce innovations 


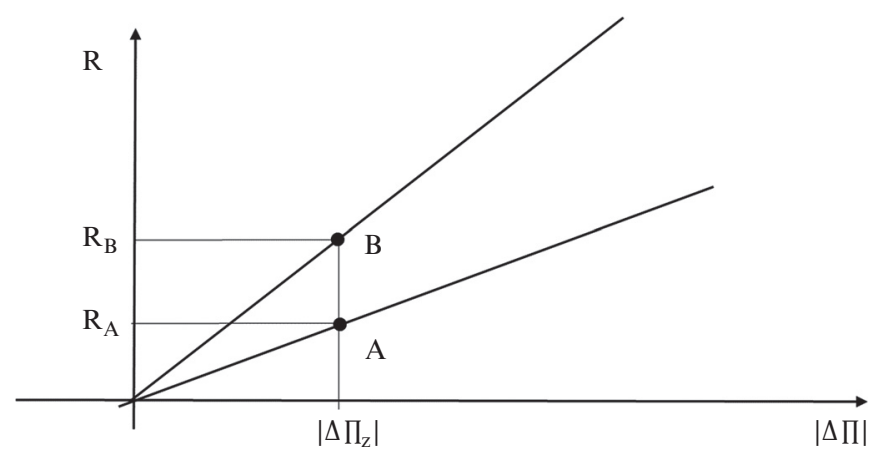

Figure 1.2 Levels of reactivity and research effort

when large knowledge externalities that reduce access costs to the stock of quasi-public knowledge are made possible by the quality of knowledge governance mechanisms at work within the system.

Figure 1.2 shows that at the same level of out-of-equilibrium conditions measured by the difference in absolute terms between profitability and performance and the normal levels of profitability and performance $\left(\Delta \Pi_{z}\right)$ there are two quite different levels of research efforts: $R_{A}$ with low levels of reactivity and $R_{B}$ with high levels of reactivity. The levels of reactivity play a major role in assessing the elasticity of the system to out-of-equilibrium conditions.

The implications of this analysis are important to assess the actual determinants of the innovative efforts of an economic system. The amount of research is likely to be larger in systems characterized not only by widespread out-of-equilibrium conditions than in systems where all firms operate near equilibrium and the variance of profitability and performance at large is small, but also by high rather than low levels of reactivity.

These implications can be amplified when we measure out-of-equilibrium conditions in terms of variance with respect to average profitability and performance rather than with respect to normal profitability and performance. When average profitability and performance is taken into account as the relevant measure of out-of-equilibrium conditions we expect that in systems with average profitability and performance above normal levels but low levels of variance the reactivity is always lower than in systems where out-of-equilibrium conditions are measured with respect to normal profitability and performance. The greater the variance with respect to the average, the larger the chances that firms try to react. When the outof-equilibrium conditions of each firm refer to average profitability and performance it becomes immediately clear that the larger is the variety 
and heterogeneity of firms, the larger the innovative efforts. With greater research efforts, and given levels of knowledge externalities, there are greater chances of faster rates of introduction of innovation and increase of total factor productivity and ultimately economic growth.

The results of the replicator analysis, according to which the greater the variety of firms the larger the growth rates, are confirmed, overcoming the Darwinistic and exogenous assumptions of the replicator analysis (Metcalfe, 1998).

The replicator analysis, in fact, assumes the heterogeneity of firms in terms of given and exogenous, or randomly determined, differences in fitness among species competing for scarce resources in a given environment. The larger the variance in terms of levels of fitness, the larger the rates of growth simply because the eventual survival of the species with higher fitness parameters and the exit of the weaker ones leads to a larger population and faster rates of growth along the substitution process.

In the approach outlined so far, instead, the larger is the variety and heterogeneity of firms, the larger are the research efforts that may eventually lead, with high levels of knowledge externalities provided by the system, to a faster rate of introduction (and creative adoption) of technological innovations, and hence larger rates of increase in total factor productivity (TFP). The positive relationship between heterogeneity, variety and variance of profitability, performances and rates of growth is confirmed. The determinants of the relationship, however, are completely different. In the standard replicator analysis, innovation is exogenous. Growth is determined by the diffusion of the exogenous innovation. In the analysis implemented so far, innovation is endogenous.

\section{LEVELS OF KNOWLEDGE GOVERNANCE AND THE CREATIVE RESPONSE}

The creative response of firms to out-of-equilibrium conditions is contingent upon the actual costs of knowledge. Knowledge costs are determined by the knowledge externalities available in the system. Knowledge externalities are pecuniary and diachronic. They make possible the use of knowledge spillovers at costs that are below the equilibrium levels of knowledge as a standard good. In turn the amount of knowledge externalities available in a system depends upon the quality of knowledge governance mechanisms at work in a system (Antonelli, 2017a, b).

Knowledge governance consists in the structure of knowledge generation activities; the organization of the architecture of knowledge of interactions and transactions; and the institutional set-up that makes the 
accumulation of the stock of quasi-public knowledge possible and enables the use of that knowledge at low costs (Ostrom and Hess, 2006).

Because of the limited appropriability of knowledge, inventors can retain full control of the economic benefits stemming from the new technological knowledge they have generated only for a limited stretch of time. After that appropriation window, technological knowledge becomes a quasi-public good and contributes to the accumulation of a stock of quasipublic knowledge that third parties can try to access as an indispensable complementary input in the recombinant generation of further knowledge (Weitzman, 1996).

High-quality knowledge governance mechanisms favour knowledge interactions along the vertical stages of the inter-sectoral division of labour with effective user-producer interactions that also include final markets, effective knowledge transmission between public and private research centres. They also reduce the exclusivity of intellectual property (IP) rights so as to support both the necessary rewards of knowledge producers and the widespread secondary uses of proprietary knowledge for the recombinant generation of new knowledge (Antonelli, 2015b).

The quality of knowledge governance mechanisms at work in the system plays a central role in this process on two counts: first, accumulation of the knowledge spilling from 'inventors' into the stock of quasi-public knowledge is contingent upon the quality of the knowledge governance mechanisms. In systems with poor knowledge governance mechanisms the uncontrolled spillover of knowledge dissipates in the atmosphere and results in slow rates of accumulation of the stock of quasi-public knowledge. In contrast, knowledge spillover effectively adds to the existing stock of quasi-public knowledge in systems endowed with high-quality knowledge governance mechanisms and low levels of dissipation. Second, access to and use of knowledge spilling from third parties accumulated in the stock of quasi-public knowledge is not free. Relevant absorption costs are necessary in order to search, identify, decode, access and finally (re)use the knowledge available in the system. Knowledge absorption costs are reduced by effective knowledge governance mechanisms that favour search, screening and access to existing knowledge for new uses.

The actual levels of knowledge externalities, and hence of the costs of external knowledge, are determined by the amount of quasi-public knowledge and the amount of absorption activities that are necessary to benefit from and use it. When high-quality knowledge governance mechanisms are at work, firms can access external knowledge at low costs, far below equilibrium levels, both because of low absorption costs and the large amount of quasi-public knowledge. Productivity-enhancing innovations depend upon the actual access to knowledge spillovers that make external 
knowledge indispensable in the recombinant generation of new knowledge, available at costs that are below equilibrium levels. In these systems, consequently, firms that try to cope with out-of-equilibrium conditions have more chances to implement creative responses and introduce technological innovations that reshape the map of isoquants.

Firms embedded in systems with poor knowledge governance mechanisms experience high absorption costs of knowledge spillovers. The final costs of external knowledge are larger, actually close to the levels of knowledge costs if it were a standard economic good. These firms cannot take advantage of knowledge externalities. Their response to emerging outof-equilibrium conditions is consequently adaptive. They try to cope with out-of-equilibrium conditions by means of technical changes that enable them to move on the existing map of isoquants.

The introduction of productivity-increasing innovations is strictly contingent upon the properties of the system. For given levels of reactivity, the response of firms is actually creative according to the amount of knowledge externalities available in the system and their success - in terms of actual introduction of productivity enhancing innovations - is ultimately determined by: i) the actual costs of the external knowledge that is an indispensable input strictly complementary to the research efforts in the recombinant generation of new knowledge; and ii) the actual bottomline costs of the knowledge that enters the technology production function as a complementary input alongside the traditional tangible ones such as capital and labour.

Hence, for given levels of reactivity, a system and each agent within the system have more chances to select a creative rather than an adaptive response to out-of-equilibrium conditions, according to costs of access to the stock of quasi-public knowledge that, in turn, depend upon the quality of knowledge governance mechanisms at work in the system.

This result complements the outcome of the previous section according to which, for given levels of knowledge externalities, the larger the levels of reactivity, the larger the research efforts and hence the rate of introduction of innovations.

The analysis also makes it clear that the quality of knowledge governance mechanisms is fully endogenous: it is continually shaped and reshaped by firms' conduct, by their levels of reactivity and by the actual rates of generation of new technological knowledge and eventual introduction of innovations. The quality of knowledge governance mechanisms may stay put through time, as well as improve and deteriorate. These processes are typically non-ergodic and yet far from deterministic: typically path rather than past dependent. 


\section{THE DYNAMICS OF THE CREATIVE RESPONSE: A GRAPHIC EXPOSITION}

The elements introduced so far to explore the role of the engines of creative response can now be nested into a fully fledged system of interdependence that relates creative response to levels of reactivity, and hence to the actual amount of research that takes place in a system, the consequent amount of technological knowledge that can be generated taking into account levels of knowledge externalities and, consequently, the extent to which the response is creative and its effects in terms of the rate of introduction of innovations and the amount of output and TFP that can be achieved (see the Appendix).

Quadrant I of Figure 1.3 (starting from northwest) reproduces simply Figure 1.2. Starting with a given level of $\Delta \prod$, the margin of actual profitability and performances with respect to normal (average) profitability, this quadrant shows the effects of different levels of reactivity. With high levels of reactivity, firms are induced to the innovative effort $R_{B}$ clearly larger than $R_{A}$ that would take place with low levels of reactivity.

Quadrant II represents knowledge generation activities. ${ }^{2}$ Knowledge generation activities are far more productive when they can rely upon strong knowledge externalities that enable firms to access the stock of quasi-public knowledge at low costs. The innovative efforts yield a larger knowledge output ( $\mathrm{T}$ ), respectively found in $\mathrm{F}$ and $\mathrm{G}$ for more and less reactive firms. When knowledge externalities do not support the generation of technological knowledge and access costs to the stock of the quasi-public

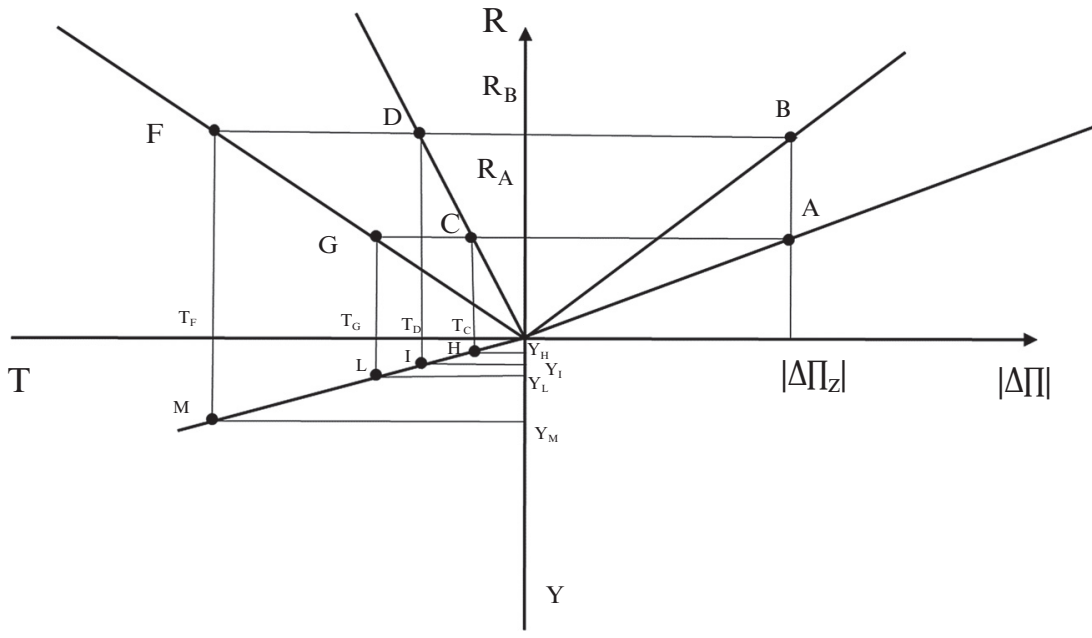

Figure 1.3 The dynamics of the creative response 
knowledge are close to the equilibrium levels of knowledge - that is, as if it were a standard economic good with high levels of exhaustibility and appropriability ${ }^{3}$ - output is lower: respectively $\mathrm{D}$ and $\mathrm{C}$ for more and less reactive firms.

Quadrant III shows production activities. Technological knowledge (T) enters the production function as an input alongside the traditional tangible inputs, capital and labour. Assuming fixed levels of capital and labour, this quadrant shows the effects of the larger amount of technological knowledge generated in Quadrant II on the production of output (Y). For given levels of reactivity, when $\mathrm{T}$ is larger than in equilibrium because of the positive effects of knowledge externalities, $\mathrm{Y}$ is larger than it would be when $T$ matches equilibrium levels. As Quadrant III shows, when reactivity levels are high $\left(\mathrm{R}_{\mathrm{B}}\right)$ and knowledge externalities are effective, knowledge output $T_{F}$ is larger than $T_{D}$ at the levels that take place when knowledge externalities do not support the generation of knowledge at costs that are below equilibrium levels. By the same token, when reactivity levels are low $\left(\mathrm{R}_{\mathrm{A}}\right)$ and knowledge externalities are effective, knowledge output $T_{G}$ is larger than $T_{C}$ at the levels that take place when knowledge externalities do not support the generation of knowledge at costs that are below equilibrium levels. The distances on the inferior vertical axis $-\left(T_{G} T_{C}\right)$ and $\left(T_{F} T_{D}\right)$ - measure the effects of the lower costs of technological knowledge on output $\mathrm{Y}$ and, as such, provide a reliable clue to the effects of knowledge externalities on total factor productivity.

It is clear that a system endowed with high levels of both the reactivity of firms and the quality of knowledge governance mechanisms is better able to increase not only its rates of growth but also, and most importantly, its rates of increase of TFP: $\left(T_{G} T_{C}\right)>\left(T_{F} T_{D}\right)$.

Firms' levels of reactivity to out-of-equilibrium conditions and the quality of knowledge governance mechanisms that defines the actual amount of knowledge externalities are the drivers of the creative response. The larger the reactivity of firms and the higher the quality of the knowledge governance mechanisms, the larger the rates of introduction of innovations, as measured by the amount of technological knowledge generated, and the growth of both output and TFP.

The system of interdependencies framed in Figure 1.1 provides the building blocks to explore Quadrant IV and to study the dynamics of the system. It is in fact clear that:

- The larger the variance of profitability and performances levels, the higher the reactivity levels and the larger the amount of research efforts. 
- The larger the amount of research efforts and the lower the costs of accessing and using the stock of quasi-public knowledge, the lower is the actual output of the knowledge generation activities. With a given budget firms that enjoy relevant knowledge externalities can take advantage of costs to access the stock of quasi-public knowledge that are below equilibrium levels and can generate more knowledge at costs that are below equilibrium.

- The larger the knowledge output, the lower its costs and the larger the output $\mathrm{Y}$ of the technology production function and the levels of TFP.

- The dynamics of the system for given and invariant levels of the quality of knowledge governance mechanisms exhibits the typical traits of a self-sustained process supported by positive feedback.

- Because of the working of diachronic knowledge externalities according to which the flows of proprietary knowledge add to the stock of quasi-public knowledge, after a limited window of appropriation the larger the knowledge output at each point in time and, for invariant levels of knowledge governance, the larger the stock of quasi-public knowledge. Hence the lower are its costs and, consequently, knowledge costs are lower and the chances that firms are able to implement an effective creative response are higher.

- The faster innovations are introduced and the larger the growth of TFP, the larger are likely to be the unexpected changes in factor and product markets that are at the origin of out-of-equilibrium conditions levels of variety within the system. Variety and heterogeneity are more likely to be persistent, and actually may amplify in systems characterized by fast introduction of innovation. A virtuous self-feeding process of creative disorder can actually enter in place, provided the quality of knowledge governance mechanisms is also persistent.

- The lower the rates of introduction of innovation, due to low-quality knowledge governance mechanisms, and hence slow accumulation of the stock of quasi-public knowledge and high costs to access it, the lower the chances that creative responses actually can take place. The prevalence of adaptive responses reduces the heterogeneity of firms. The typical Marshallian search for equilibrium displays fully its effects: worst-performing firms are sorted out and the benchmark quality of outstanding ones is rapidly imitated by all the other firms. At the end of the Marshallian process heterogeneity is substituted by homogeneity, and equilibrium conditions prevail.

The quality of knowledge governance mechanisms is fragile and fully exposed to events that may take place along the process and change it. The 
generation of new technological knowledge and the introduction of new technologies, at each point in time, can change (sometimes radically) the structure of the system, the organization of knowledge interactions and transactions, the architecture of knowledge networks and the institutional setting that qualify the knowledge governance mechanisms. Consequently, the system dynamics is path dependent, as opposed to past dependent, as it exhibits strong historic, non-ergodic elements, such as the amount of quasi-public knowledge, that depend upon the accumulation of generation flows. At the same time it is also exposed to possible degeneration of the quality of knowledge governance mechanisms brought about by the very dynamics of the process.

The decline in quality of knowledge governance mechanisms can easily stop the system dynamics, with two distinct negative effects: first, it reduces the rates of accumulation of the flows of new technological knowledge, and hence the increase in the stock of quasi-public knowledge. This has direct negative effects on the rates of reduction of the access costs of external knowledge that firms use as a necessary complementary input in the recombinant generation of new technological knowledge. Second, it increases the levels of absorption costs, and thus may actually lead to an increase in the cost of external knowledge. The consequences are clear. The likelihood that firms can implement creative, rather than adaptive, responses declines with the consequent reduction in rates of technological change and increase in total factor productivity.

\section{CONCLUSIONS}

The notion of creative response is at the same time the synthesis of the Schumpeterian legacy and the foundation stone of a comprehensive platform that uses the tools of evolutionary complexity able to accommodate in a coherent framework the understanding of endogenous innovation as an emergent system property. The notion of creative response enables us to go beyond the limitations and shortcomings of the evolutionary approaches that build upon biological metaphors. Innovation can be analysed as the outcome of the interdependence between individual decision-making and the properties of the system in which it takes place. The outcome of individual decision-making - the actual introduction of innovations - depends upon the characteristics of the system. The latter in turn is influenced by the outcomes of individual decision-making.

This chapter has explored the engines of the creative response: the levels of firms' reactivity to out-of-equilibrium conditions and the properties of the system that support the creative response with the provision of 
knowledge externalities that enable innovating firms to access and use the stock of quasi-public knowledge to generate new knowledge at costs that are below equilibrium levels.

The analysis has shown that low levels of reactivity reduce the amount of innovative efforts a system is able to mobilize. At the same time, high levels of reactivity without the support of appropriate levels of knowledge governance favour the rapid return to equilibrium levels, but not the actual introduction of innovations. High-quality knowledge governance mechanisms coupled with low levels of reactivity lead to slow rates of introduction of innovations and slow rates of increase in output and total factor productivity. In contrast, a system characterized by high levels of reactivity and high levels of knowledge governance enables firms to implement creative responses that lead to rapid introduction of innovation and fast rates of increase in output and TFP.

Systems characterized by high-quality and consistent knowledge governance mechanisms and reactive managerial styles are likely to experience rapid introduction of innovations that feeds persistent growth via: i) the recreation of out-of-equilibrium conditions; ii) the accumulation of the stock of quasi-public knowledge; iii) the quality of knowledge governance mechanisms; and iv) the persistence of knowledge externalities. In such systems creative disorder is persistent and may last as long as the quality of knowledge governance mechanisms is able to cope with the dynamics of the system and is fortified rather than damaged by it. An endogenous loop of positive feedback supports the growth of the system and the persistence of out-of-equilibrium conditions.

Systems characterized by low-quality knowledge governance mechanisms and managerial styles with low levels of reactivity are doomed to converge rapidly to equilibrium. The Marshallian search for equilibrium prevails when adaptive responses prevail over creative ones. The adaptive response prevails when the quality of knowledge governance mechanisms is poor, and, consequently, the amount of knowledge generated at each point in time is small and cumulates slowly, the access and secondary use costs of the stock of quasi-public knowledge are high, and search activities enable firms to engage in technical rather than technological changes. The variance of firms is quickly reduced by the exit of the worst-performing ones and the imitation of the advanced ones. Variety decreases together with variance and the slowdown of the rates of innovation, of increase in total factor productivity and in growth of output.

The implications for economic policy are clear. First, a managerial style able to integrate high levels of entrepreneurship helps improve system performance. The dichotomy between entrepreneurs and managers, where the former are associated with small firms and start-ups and the latter 
with incumbent corporations, should be abandoned. Creative managers of large corporations are just as necessary as competent entrepreneurs in small firms and newcomers. Second, the quality of the knowledge governance mechanisms that rule the accumulation of the stock of quasi-public knowledge and its access and secondary use at low costs is a central asset of an economic system that assigns a central role to the rate of introduction of technological and organizational innovations.

Public policy should care about: the architecture of inter-sectoral flows of knowledge along the multi-stage user-producer interactions; the quality of the public research infrastructure; the interface between public and private research centres; the mobility of skilled personnel among and between firms and the public research system; the working of the knowledge markets; the role of knowledge-intensive business services (KIBS); the exclusivity of intellectual property rights so as to favour at the same time the appropriation of economic benefits stemming from the introduction of innovations as well as the useful dissemination and secondary uses of existing technological knowledge.

\section{NOTES}

1. In Figure 1.1 the quadratic relationship is symmetric: the response of firms to performances above and below the average is specular in shape. Internal financial constraints and credit rationing might reduce the ability of firms with below average performance - and even more below normal levels of profitability - to fund the necessary research activities. At the same time, however, firms performing above the average may use part of their profits to pay higher dividends to shareholders and higher wages to employees, and to fund other stakeholder benefits, reducing the amount of resources that can be used to fund internal R\&D. The actual shape of the quadratic relationship is determined by the institutional set-up of financial markets, intellectual property rights, industrial relations, and product and factor markets.

2. The geometric representation posits contant returns to scale in knowledge generation activities. Diminishing returns to scale might be easily accommodated with a negative second derivative without altering the basic relationship.

3. Arrow (1962) identifies the special features of knowledge such as limited appropriability and exhaustibility, substantial indivisibility, cumulability and complementarity, and low costs of reproduction by confronting knowledge with respect to standard economic goods. The negative effects of the limited appropriability of knowledge on the incentives to its generation, with high-quality knowledge governance mechanisms and substantial levels of knowledge cumulability and indivisibility, can be more than compensated for by their positive effects in terms of spillovers and the consequent reduction in costs of knowledge below equilibrium levels. 


\section{APPENDIX: A SIMPLE MODEL}

Following the literature that impinges upon the constructionist design methodology (CDM) approach (Crépon et al., 1998), analysis of the engines of the creative response can be framed in a simple system of equations: i) the research function; ii) the knowledge generation function and its cost equation; iii) the external knowledge cost equation; and iv) the technology production function. Let us introduce them in turn.

The research function summarizes the relationship between out-ofequilibrium conditions as measured by $\Delta \Pi$, that is, the difference between the levels of profitability and performance of each firm and normal ones in absolute terms - in other words, taking into account both profit and performance above and below the norm:

$$
\mathrm{R}=\mathrm{f}(\mathrm{j} \Delta \Pi)
$$

where $\mathrm{j}$ measures the levels of reactivity.

The knowledge generation function formalizes the relationship between research efforts $(\mathrm{R})$ and the actual output of knowledge $(\mathrm{T})$ taking into account the stock of quasi-public knowledge (SQPT) available in the system, where $m$ and $n$ are their output elasticity. The Cobb-Douglas specification of the knowledge generation function makes explicit the strict complementarity between the stock of external knowledge drawn from the stock of quasi-public knowledge available in the system and the flow of internal research efforts. The cost equation includes on the left-hand side the amount of the research budget $(\mathrm{R})$ that has been determined by equation (1A.1) and, on the right-hand side, the unit costs (r) of (R\&D) activities and the search costs $(\mathrm{u})$ that enable firms to access and use the stock of quasi-public knowledge:

$$
\begin{gathered}
\mathrm{T}=\mathrm{h}\left(\mathrm{R}^{\mathrm{m}} \mathrm{SQPA}^{\mathrm{n}}\right) \\
\mathrm{R}=\mathrm{rR} \& \mathrm{D}+\mathrm{uSPQT}
\end{gathered}
$$

The size of the stock of quasi-public knowledge is fully endogenous. Because of diachronic knowledge externalities, in fact, it depends on the amount of knowledge flows that have been generated in previous time periods and the quality of knowledge governance mechanisms (KGM) that rule their accumulation process:

$$
S Q P T=l\left(K G M,\left(\sum_{t=n}^{N} T_{t}\right)\right)
$$


The costs of accessing and using the stock of quasi-public knowledge are also endogenous as they depend on its size (SSPQT) and KGM:

$$
\mathrm{u}=\mathrm{m}(\mathrm{SSPQT}, \mathrm{KGM}), \text { where } \mathrm{h}^{\prime}<0
$$

The unit cost of technological knowledge (z) is now fully endogenous:

$$
\mathrm{z}=\mathrm{R} / \mathrm{T}
$$

Finally, the technology production function specifies the relationship between output (Y), the standard inputs capital (K) and labour (L) and knowledge $(\mathrm{T})$ produced in the upstream knowledge generation function, with their respective output elasticity $\alpha, \beta$ and $\gamma$. Next to it is the standard cost equation, where $r$ measures capital user costs, w wages and $z$ the actual level of the cost of knowledge generated upstream that takes into account the effects of knowledge externalities. Equation (1A.7) includes the measure $(\mathrm{A})$ of total factor productivity:

$$
\begin{aligned}
& Y=A\left(K^{\alpha} L^{\beta} T^{\gamma}\right) \\
& C=r K+w l+z T
\end{aligned}
$$

Because $z \mathrm{~T}=\mathrm{R}$, it is evident that, for endogenous levels of $\mathrm{R}$ the lower the endogenous levels of $z$, the larger is T. Hence the levels of TFP are determined by the difference between the equilibrium levels of the cost of knowledge ( $\mathrm{g}$ ) that would take place if it were a standard economic good and the actual costs of knowledge ( $\mathrm{z}$ ) that take into account the effects of upstream knowledge externalities:

$$
\mathrm{A}=\mathrm{n}(\mathrm{g}-\mathrm{z})
$$

When $\mathrm{z}=\mathrm{g}$ firms are not able to introduce productivity-enhancing innovations. The introduction of such innovations takes place only when $g>$ $z$, when the generation of technological knowledge can rely on effective knowledge externalities that reduce the cost of external knowledge (u) below equilibrium levels so that also the costs of technological knowledge (z) as an intermediary and yet indispensable input in the technology production function are below equilibrium levels g (Antonelli, 2013a, 2017a, b). 